\title{
RACE AS TECHNOLOGY: FROM POSTHUMAN CYBORG TO HUMAN INDUSTRY
}

\author{
Holly Jones \\ The University of Alabama in Huntsville \\ Huntsville, USA. \\ Nicholaos Jones ${ }^{* *}$ \\ The University of Alabama in Huntsville \\ Huntsville, USA.
}

\begin{abstract}
Cyborg and prosthetic technologies frame prominent posthumanist approaches to understanding the nature of race. But these frameworks struggle to accommodate the phenomena of racial passing and racial stationarity, and their posthumanist orientation blurs useful distinctions between racialized humans and their social contexts. We advocate, instead, a humanist approach to race, understanding racial hierarchy as an industrial technology. Our approach accommodates racial passing and stationarity. It integrates a wide array of research across disciplines. It also helpfully distinguishes among the grounds of racialization and conditions facilitating the impacts of such racialization.
\end{abstract}

Keywords: Eyeborg; Haraway; industrial technology; humanism; racial hierarchy

\section{Introductory Remarks}

Racial classifications sort humans into racial groupings regardless of their consent. These groupings tend to be hierarchical, with each group's members experiencing distinctive harms and benefits by virtue of their group's position in the hierarchy (see Magee and Galinsky; Bashi and McDaniel 671; Bashi 966; Conley; Mills; Vogel). Here we ask: What is it to be racialized as a human being? What is it, for example, to be white, black, Asian, or Hispanic in the United States of America? Or to be branco, pardo, preto, amarilo, indígina in Brazil (Santos et al)?

Our question is not whether race is real or illusory, or whether biological, social, or agential factors ground racial hierarchies. We leave such issues to metaphysicians. Nor is our question about how racial classifications affect those in different positions within a racial hierarchy. We leave this to sociologists. Our question, rather, concerns how to understand the interconnectedness of a person's humanness and their race. We ask this question amidst a surge of interest for theorizing race as some sort of technology. Consider four examples. Falguni Sheth, a political philosopher, interprets race as a technology that legitimates violence and exclusion while concealing its nature and function. Wendy Chun, a media theorist, interprets race as a technology that positions whites as human and Asians as robotic. Beth Coleman, a comparative literary theorist, interprets race as a technology that extends our capacity for autonomous agency. Ruha Benjamin, a sociologist, interprets race as a technology for creating and maintaining inequality ("Innovating Inequality").

Our essay focuses on posthumanist approaches to theorizing race as technology. These approaches understand racialized humans as posthuman,

\footnotetext{
${ }^{*}$ Associate Professor of English at University of Alabama in Huntsville. PhD. Research Areas: Ethnic American Literature and Citizenship Studies. Her e-mail is dr.holly.jones@gmail.com.

** Associate Professor of Philosophy at The University of Alabama in Huntsville. PhD. Research Areas: Philosophy of Science and Asian Philosophy. His e-mail is
} njj0001@uah.edu. 
fundamentally distinct from mere humans. This might seem to be a natural approach to theorizing race as technology, insofar as technology carries connotations of allowing (or tempting) us to transcend human limitations. But this posthumanist approach has received relatively scant attention, because posthumanist paradigms tend to bypass "a more comprehensive examination of the role of race in "the human's' metaphysics" (Jackson, "Outer Worlds” 216). There are worries, moreover, that posthumanist approaches to race are "persistent bourgeois attempt[s] to reduce the most human problems to comfortable, hollow notions" (Césaire 62; also see Jackson, "Animal" 672).

We aim to explore these worries by engaging with a posthumanist interpretation of cyborgs. Cyborg theorizing has tended to evade issues of race (Wilkinson 170; see also Schueller 77-82), but this is changing. Recent scholarship by both Jasbir Puar and Margaret Rhee, for example, invokes the notion of cyborg in efforts to better integrate posthuman theorizing with theories about racial classification and hierarchy. Puar interprets race as cyborg technology for its potential to avoid privileging bodies as human. Rhee, extending Puar's interpretation, invokes the cyborg as exemplifying the way race reconfigures what she calls our "agentic activities."

We argue that the posthumanist interpretation of racialized humans as cyborgs, despite its several virtues, does not properly accommodate the empirical realities of race. The concept of the cyborg has rich conceptual associations, many of which align with aspects of race that tend to be ignored or under-theorized. But, in our view, theorizing racialized humans as cyborgs inhibits properly understanding the diverse ways in which social contexts-conditions external to and separable from human bodies-create and sustain racial classifications and hierarchies.

We advocate an alternative, humanist interpretation of racial hierarchies as industrial technologies. This facilitates understanding how social contexts constitute and create conditions in which human organisms live and move and have their being. It supports an alternative explanation for how race reconfigures our agentic activities: not, as with cyborgs, because race is an inexplicable part of our identities, but because human industrial institutions and infrastructures shape the impacts and available use-functions of race as a technology. It also gestures toward correlations, and potential connections, between industrial revolutions and modern racial hierarchies.

We locate our analysis in the context of race as it has developed in the United States of America. Much of the philosophical and scientific scholarship with which we are familiar focuses on this context, and we offer references as guides for exploring that context. We suspect that our analysis extends to other contexts, but we leave this work for another occasion. We intend our argument as contributing a partial remedy to "the lack of suitable critical schemes to scrutinize the present" (Braidotti, Posthuman 4).

\section{Posthuman Promises}

The notion of human as sovereign and autonomous consciousness fits poorly with lived human experiences. Environmental factors, both social and natural, influence our minds in subtle and unconscious ways. Our bodies are diverse, and corporeal difference often tracks differences of agential capacity-for example, male bodies command kinds of power and respect unavailable, or available only at great cost, to female ones. Posthumanism infers from this mismatch that we ought to understand ourselves as posthuman rather than human.

N. Katherine Hayles understands the notion of posthuman as a cluster concept. The posthuman, according to Hayles, prioritizes informational exchange over corporeal biology, consciousness as epiphenomenal rather than agential, bodies as technological prosthesis rather than privileged locus of behavior, and human beings as continuous with artificial and cybernetic forms of life (2-3). Hayles contrasts the posthuman, so understood, with a notion of human prevalent from early modern European philosophy: a mind who naturally owns its corporeal body, who uses consciousness to enact its will and control its bodily behaviors, and who stands apart from others-animal and machine alikeby virtue of its capacity for autonomous action (3). 
Braidotti offers a similar contrast. The human, for Braidotti, has an inexhaustible capacity for authenticity and self-realization, a consciousness capable of transcending spatiotemporal particularities and geographical boundaries in order to access timeless and universal truths, and a rational mind that controls the body while imposing meaning and value upon the world (Posthuman 13-22). The posthuman, by contrast, is complex and relational rather than unitary and selfsufficient; affective and embodied rather than rational and incorporeal; multiply fragmented and local rather than coherently unified and universal (Braidotti, Posthuman 26-28).

Despite these similar conceptualizations, there is something about the posthuman that resists categorization. Braidotti hints at the source of resistance:

Not being framed by the ineluctable powers of signification, [the posthuman] is consequently not condemned to seek adequate representation of its existence within a system that is constitutionally incapable of granting due recognition. (Posthuman 188)

Thweatt-Bates makes a similar observation, characterizing the notion of posthuman as

a way of naming the unknown, possible, (perhaps) future, altered identity of human beings, as we incorporate various technologies into our bodies and selves. It therefore functions as an umbrella term, covering a span of related concepts: genetically enhanced persons, artificial persons or androids, uploaded consciousnesses, cyborgs and chimeras (mechanical or genetic hybrids). (1)

Accordingly, while the posthuman differs from the human, these differences do not exhaust the meaning of posthuman. The posthuman is fundamentally ineffable, resisting the fixity of conceptualization, unconfined by well-defined categories, open to unconceived futures incommensurable with the present (also see Hayles 283-287; Ferrando 30).

Simultaneous with its ineffability, the posthuman seems to offer a framework for making sense of our social condition-full of inequality, negativity, and oppression of many sorts-and imagining better futures. There is an overwhelming body of empirical evidence about the harmful impacts of racial hierarchies upon members of oppressed races (Song). There is also a growing social desire-well represented by the Black Lives Matter and We Are Here movements in the United States-for ameliorating or preventing those harms (see Edwards and Harris). So we should expect the notion of posthuman to facilitate insightful theorizing about racial hierarchies-their grounds, their impacts, and effective strategies for reformation and transformation toward racial justice.

\section{Against Cyborgs}

\subsection{Posthuman Identity as Cyborg Identity}

Of the many visions available for theorizing within a posthumanist orientation, the cyborg ranks among the most influential and suggestive (see Braidotti, "Posthuman;" Thweatt-Bates 5; Ferrando 28; Kull 51). The vision of the cyborg originates with Donna Haraway, who characterizes it as "a kind of disassembled and reassembled, postmodern collective and personal self" (163). That is, according to Haraway, the cyborg is "a cybernetic organism, a hybrid of machine and organism, a creature of social reality as well as a creature of fiction" (149). Cyborgs are hybrids, because their machinic and organismal components are inseparable, neither capable of existing as it is apart from the other. These hybrids are creatures of social reality, because existing networks of social relations prioritize some syntheses over others, and because different hybridizations live different social experiences. But cyborgs are creatures of fiction, too, by virtue of existing as social and political constructions, so that different constructions ground alternative hybrid potentials.

Braidotti classifies Haraway's vision of cyborgs as "high-post-humanism," subject to the caveats that Haraway herself disavows the posthumanist label and that Haraway understands her work on companion species as subsuming earlier work on cyborgs (Braidotti, "Posthuman" 197-198). But whether cyborgs 
offer a vision of the posthuman is quite independent of Haraway's intellectual preferences. For the notion of cyborg lends itself to posthuman theorizing (see Kull 51). Cyborg anthropology, for example, argues that

human subjects and subjectivity are crucially as much a function of machines, machine relations, and information transfers as they are machine producers and operators. (Downey, Dumit, and Williams 266)

Chela Sandoval sketches how to realize the theoretical promise of the cyborg concept in the context of racial oppression. She argues that oppressed races enact five methodologies for achieving autonomy within harmful racial hierarchies: reading cultural signs, challenging signs from dominant ideologies by separating sign from intended meaning, appropriating those signs by investing them with new meaning, orienting such deconstructive efforts toward building egalitarian social relations, and selecting appropriate behaviors to enact those efforts (Sandoval 376). Sandoval proposes that because cyborgs also challenge conventional meanings, by virtue of expanding human capacities, we can better understand how these methodologies, employed by racialized humans, work by theorizing them as enacted by cyborgs (Sandoval 381-383).

Neil Harbisson's Eyeborg illustrates the spirit of Sandoval's analysis, albeit without the racial context. Born only with the capacity to see black and white, Harbisson wears a device-an Eyeborg-that converts colors into sounds. Over time, the Eyeborg has altered his neural pathways, giving him new capacities for visualizing the world (see Alfaro et al). Harbisson can "read" visual signs, but his unconventional readings allow him to invest common activities with new meaning. For instance, he can compose music by "viewing" mosaics, and he paints voice performances (Pearlman). Harbisson's cyborg capacity for hearing colors thereby challenges conventional separations of sound and vision, outside of which he had previously been positioned. Similarly, Sandoval's proposal to categorize the methodologies enacted by oppressed races as cyborg technologies would seem to suggest that efforts to challenge harmful racial hierarchies are best understood as cyborg, rather than human, activities.

\subsection{Theorizing Racialized Humans as Cyborgs}

Haraway's vision of the cyborg is designed to subvert "the tradition of racist, male-dominant capitalism" by destabilizing borders between self and other, autonomous organism and deterministic machine (Haraway 150). Haraway contends that,

\begin{abstract}
Gender, race, or class consciousness is an achievement forced on us by the terrible historical experience of the contradictory social realities of patriarchy, colonialism, and capitalism. (155)
\end{abstract}

These contradictory realities limit phenomenological possibility. For example, when colonial ideology reserves personhood for whites to the exclusion of blacks, while patriarchal ideology reserves personhood for men to the exclusion of women, black women inherit only "a cascade of negative identities," ignored not only by feminists combating patriarchy but also by anti-imperialists resisting colonialism (Haraway 156).

The vision of black women as cyborgs avoids this cascade of negativities. As a cyborg identity, "woman of color" is "a potent subjectivity synthesized from fusions of outsider identities" (Haraway 174). Black women thereby gain positive identity as hybrid integrations of human organism, on the one hand, and the dual social constructions of "woman" and "black," on the other. These cyborgs derive power from their existence on the margins of patriarchal and colonialist ideologies (Haraway 176). This power makes them capable of surviving and thriving by virtue of seizing as their own the stories, language, and tools used to mark them as other or erase them from view (Haraway 175-176). In doing so, black women as cyborgs problematize "the statuses of man or woman, human, artefact, member of a race, individual entity, or body" (Haraway 178). They thereby undermine fundamental supports for gender and racial injustice.

Such, in rough outline, is the significance for racial justice and activism of envisioning the posthuman 
as cyborg. Whence Haraway's remark that "Cyborg imagery can suggest a way out of the maze of dualisms in which we have explained our bodies and our tools to ourselves" (181).

We acknowledge that envisioning racialized humans as cyborgs stimulates creative exploration of alternative social and political possibilities. We note, further, the power of that vision to explain lived realities of racialized humans. For example, theorizing people of color as cyborgs helps to explain their unequal or oppressive treatment, because cyborgs themselves are often de-humanized, treated as less than fully human, or conceptualized as threats to established social order. Similarly, theorizing race as a fundamental component of cyborg identity helps to explain why racial colorblindness is a myth: because the fundamental components of cyborg identities are inseparable, a person apart from their race cannot exist as the same person (see Neville, Gallardo, and Sue).

\subsection{Passing and Stationarity}

Despite these several theoretical virtues, however, theorizing racialized humans as cyborgs does not match the empirical reality of race-at least, not without significant ad hoc adjustments. We consider two phenomena in particular: passing and stationarity (see also Mallon).

Consider, first, the phenomenon of passing, wherein a member of one racial group allows or encourages their classification by others as a member of another racial group (Ginsberg; Kennedy; Kroeger). In Philip Roth's The Human Stain, for example, the character Coleman Silk, despite being raised as black in a black family, passes as Jewish and therefore as white. Because racial passing gives members of oppressed racial groups access to social status and power reserved for members of privileged races, it has the capacity to subvert or transform harmful racial hierarchies

Consider, next, the phenomenon of stationarity, wherein membership in a racial group does not travel beyond relatively local spatiotemporal borders. Michael Root offers a vivid example of this phenomenon:
Some men who are black in New Orleans now would have been octoroons there some years ago or would have been white in Brazil today. Socrates had no race in ancient Athens, though he would be a white man in Minnesota. (631-632)

Because racial membership is stationary, traveling gives members of oppressed racial groups potential access to kinds of social status and power reserved for members of privileged races. Hence, like passing, traveling has the potential to subvert or transform harmful racial hierarchies.

Insofar as cyborg identities carry subversive capacities similar to those available through racial passing and travel, one would expect the vision of racialized humans as cyborgs to accommodate the phenomena of passing and stationarity. But it does not. Changing a cyborg's technology changes its biology. But those who change their race through passing or traveling do not change their biology. So race is not a cyborg technology.

Cyborgs are hybrids of organismal biology and machinic construction. This means that their machinic and biological components are inseparable, neither capable of existing as it is without the other. For example, Neil Harbisson with Eyeborg has fundamentally different neural pathways than Neil Harbisson without Eyeborg, and Eyeborg only functions when properly wired to active neural pathways. By analogy, this would mean that if Coleman Silk's early identity as a black man is a cyborg identity, Silk with his blackness has fundamentally different biology than Silk without blackness. Hence, if we theorize race as cyborg technology, it follows that when Coleman Silk shifts to white-by passing as Jewish-he would thereby change his biology. But this is not how racial passing works. Silk's passing as white leaves his biology intact. Similarly, if a New Orleanian's identity as a black man in New Orleans is a cyborg identity, the man with his blackness has fundamentally different biology than the man without it. Hence, if we theorize race as cyborg technology, it follows that when the New Orleanian travels to Brazil-and becomes white-he would change his biology. But this is not how racial stationarity works. The New Orleanian's journey to Brazil leaves his biology 
intact. When Silk and the New Orleanian pass and travel, respectively, their racial classifications change, not because of changes to their persons, but because of changes to the social conditions that give meaning and function to their biology. Race, in these cases, is more akin to CDMA technology in mobile phones, offering lower functionality in some contexts (Brazil) than in others (United States) despite persisting as the same hardware across those contexts.

One might object, on behalf of the cyborg vision, that nothing prevents understanding cyborgs as having chameleon identities, undergoing sudden transmutation when passing or traveling. These innovations open the conceptual possibility that the racial components for some cyborg identities are Janus-faced, now rendering the cyborg a member of one race, soon after another.

We reply that preserving the cyborg vision in this way is ad hoc. Nothing requires understanding cyborgs as having chameleon identities. This is also not how cyborgs work. When Neil Harbisson leaves his home community, others continue seeing his Eyeborg-that is, Harbisson as cyborg-even were he to somehow "turn off" the device. Moreover, were Harbisson to remove his Eyeborg, he would no longer be a cyborg even though, arguably, his neural pathways would likely take some time to reconfigure after losing the ability to hear colors. Chameleon transformations, by contrast, are more sudden, on the order of seconds rather than weeks (or longer). Coleman Silk and the New Orleanian become white the moment they enter a different racial network.

But more importantly, conceptualizing some cyborgs as chameleons undermines the power of the cyborg vision. It is the inseparable hybridity of organism and machine that gives cyborgs their positive identities and that is said to undermine a range of dualisms essential to patriarchal and colonial ideologies. Moreover, such theorizing shoulders the concept of the chameleon with the weight for explaining the phenomena of racial passing and stationarity. This casts doubt upon the theoretical value of the cyborg concept, because non-cyborgs (such as actual chameleons) also possess chameleon identities.

\section{On Racial Classification as Prosthetic Technology}

The minimal alteration of the cyborg vision capable of accommodating the phenomena of racial passing and stationarity involves theorizing race as a prosthetic technology (Coleman; Gill-Peterson). So understood, racialized humans consist of racial classifications coupled to originary bodies. Because the coupling is prosthetic, racial classification is separable from biological body. For the subjects of prosthetics preserve their bodies intact upon removal or alteration of their prosthetic. Race, so theorized, is more akin to a cane or an artificial leg, extending human capacities without altering human biology.

Envisioning race as a prosthetic technology accommodates the phenomena of passing and stationarity. Both may be understood to involve switching prostheses. Because prostheses are separable from their subjects, however, neither passing nor traveling, so understood, require saying that racial passing and travel involve biological change. There is a danger in so accommodating these racial phenomena, however. We tend to understand the bodies of those who wear prosthetics as lacking that which the prosthetic provides, as when we say, of an amputee with prosthetic legs, that her body lacks legs. By analogy, if racial classifications are prosthetics, it seems that we should understand the bodily subjects of those prostheticsthat is, human bodies-as unraced, retaining a preprosthetic state that lacks race and thereby exists prior to racial grouping. The danger here is one of succumbing to, or perhaps reinforcing, the myth of racial colorblindness.

Julian Gill-Peterson avoids this danger by insisting that posthumanism is the proper framework for theorizing race as prosthetic technology (409). According to Gill-Peterson, the posthuman, unlike the human, is always and already racialized, and universal "unraced" bodies are de facto white bodies (409). He thereby follows Beth Coleman in imagining racial classification, not as a technology that mars an otherwise pristine and pure subject, but as one that "adds functionality to the subject, helps form 
location, and provides information" (Coleman 194). Understood as posthuman subjects, originary bodies are not unraced because they always already have racial identities of some sort. Theorizing racialized humans as contingent and relatively stable alliances between posthuman bodies and prosthetic racial classifications thereby secures the several theoretical virtues of the cyborg vision while avoiding its empirical inadequacy. We have no decisive objection to this approach for understanding race. But we find ourselves discontent nonetheless.

Our concern is twofold. On the one hand, theorizing racial classification as a prosthetic technology does too much. Prosthetics are sources of functionality, and subjects bear responsibility for enacting those functions. For example, an amputee's prosthetic leg is the source of her power to walk, and the amputee is responsible not only for harms the artificial leg might inflict upon others but also for harms she risks to her body by virtue of using the prosthetic. By analogy, if race is a prosthetic technology, members of oppressed races bear responsibility for the harms and benefits associated with their racial classifications. This consequence strikes us as morally unacceptable and politically naïve.

On the other hand, theorizing race as a prosthetic technology does too little. It offers too few resources for explaining the harms of racial oppression. First, prosthetic technologies harm their users by virtue of intrinsic defect or improper usage. Racial classifications, by contrast, seem to harm their users for many more reasons. For example, social institutions such as apartheid and school segregation harm members of oppressed racial groups, but the harm does not occur by virtue of people in those groups misusing their race or because their race itself is intrinsically defective. Second, people tend to prefer prosthetics that enhance function, avoiding prosthetics that harm. So theorizing race as a prosthetic technology also fails to explain why racial passing is a rare phenomenon. Finally, people with prosthetics are typically able to separate from their prosthetics at-will: those who use a prosthetic have significant control over when and whether to wear the prosthetic. But membership in racial categories typically is not like this, and only a select few are capable of racial passing.

\section{Toward Racial Hierarchy as Industrial Technology}

The posthumanist paradigm, as we understand it, rejects the notion of the human because it rejects the idea that humans are autonomous and self-sufficient, capable of acting and existing independently of others. Posthumanism thereby blurs the boundaries between embodied subjects and their social contexts. The concepts of the cyborg and the prosthetic are natural concepts for developing this paradigm but, as we have argued, those concepts poorly accommodate various empirical phenomena associated with race. Theorizing race within the posthumanist paradigm also strikes us somewhat perverse. For, as Lewis Gordon aptly observes, members of subordinate racial groups "have struggled too long for the humanist prize" (39).

Accordingly, rather than search for a vision of the posthuman that strengthens or refines those of the cyborg hybrid and the prosthetic companion, we prefer to revisit and refine the notion of human. We propose, in particular, to theorize humans as inescapably dependent upon others for their identities and capacities despite also being distinct from those others. We theorize humans as depending upon others, because social institutions and infrastructures ground who we are and shape the choices available to us. We theorize this dependence as preserving distinction, because social institutions and infrastructures persist across changes in their human participants, and because humans are capable of moving to different social contexts without changing their bodies. We theorize that this dependence is also inescapable, because we maintain that humans are social animals. (We find especially apt a saying in Chichewa, the language of Milawi: Kali kokha nkanyama. When you are on your own, you are as good as an animal of the wild.)

Our notion of human preserves boundaries between embodied subjects and their social contexts. This allows us to interpret the social institutions that create and sustain racial hierarchies, and the infrastructures that 
shape the differential impacts of those hierarchies upon members of various racial groups, as factors that are distinct from racialized human bodies. Our notion of human also acknowledges the inescapable dependence of embodied subjects on their social contexts. This allows us to theorize human bodies as inescapably racialized by virtue of depending upon social factors that create, sustain, and shape the impacts of racial hierarchies. It also allows us to accommodate recent efforts to interpret race as something that legitimates violence, dehumanizes racial minorities, extends agential capacities, and creates inequality. We can do so by locating these functions of race in social factors that create, sustain, and shape the impacts of racial hierarchies. We leave to another occasion exploration of these applications for our notion of human.

Our goal, for the remainder of this essay, is to develop a refined humanist framework for understanding the interconnectedness of a person's humanness and their race. We offer, as an alternative to posthumanist visions of cyborgs and prosthetics, a vision of race as an industrial technology. We develop this vision in three stages: first, by explicating our notion of industrial technology; second, by interpreting some social factors upon which humans depend for their racial identities and capacities as components of an industrial technology; third, by explaining how our vision accommodates the phenomena of racial passing and stationarity. In theorizing race as an industrial technology, we are not considering the mutual production of race by technology and technology by race (Reardon). We are not focusing on interactions between technology and race, considered as separate things (Sinclair). Nor are we analogizing race as similar to industrial technology (Chun 8). Instead, we are subsuming racial hierarchy as a species in the family of industrial technologies, other species of which include automobiles and prosthetics. Our effort thereby resembles Teresa de Laureits' theorizing of gender as "the product and process of a number of social technologies, of techno-social or bio-medical apparati" (3). But we focus on industrial rather than social technology, and we focus on explication rather than application of theoretical framework.

\subsection{Industrial Technology}

We understand technology as any tool, amenable to deliberate and skillful use, which facilitates producing, transforming, or controlling something. Foucault distinguishes among four kinds of technology in this sense, with respect to the targets of tool use: signsystem technologies, directed toward meaning and significance in our lives; production technologies, directed toward things; power technologies, directed toward other humans; and self technologies, directed toward ourselves (223-228). The National Academy of Engineering's Committee on Technological Literacy likewise distinguishes among three kinds of technology, in our sense of the term, albeit with respect to tool sources: artifacts and tangible products; knowledge, processes, and techniques; and infrastructure (Pearson and Young 2-3). Tools not amenable to deliberate and skillful use, if such there be, are not technology in our sense. Nor are non-tools, such as Ellul's techniques, which are merely standardized behavioral patterns (xxv-xxvi). We understand industrial technology, accordingly, as technology grounded upon some sort of industry, where by industry we mean to refer to any relatively self-contained community of people wherein subgroups of the community divide and coordinate their labor toward creating some good or service for large-scale distribution or consumption. (Trades and crafts, by contrast, are not large-scale; and (free) markets lack coordination among divided labor.)

We find it useful to distinguish between the grounds and the conditions for industrial technologies. Grounds for an industrial technology are those factors by virtue of which the technology arises and persists. These factors include techniques (standardized behavioral patterns), technicians (those who enact techniques), raw materials (the objects upon which technicians act), and machinic institutions (for coordinating technicians). Conditions for an industrial technology, by contrast, are those factors upon which the technology relies for realizing its distinctive functions, and which shape the impacts resulting from uses of the technology. These factors include use-infrastructures, or those materials which make possible the effective use of technologies, as well 
as social institutions, those organizational arrangements that structure relations among technology users.

Consider, as an illustrative example, the automobile. The automobile is a technology: it is a tool, subject to human control, that facilitates transporting people and goods from one location to another. There is also an automobile industry, involving manufacturers, distributors, and dealers, all of whom work together to distribute automobiles on a large scale. The grounds for automobiles include techniques for manufacturing, distributing, and selling automobiles; engineers, machinists, managers, and salespersons who enact those techniques; raw materials such as steel and rubber; and assembly lines that coordinate assembly workers (machinic institution). The conditions for automobiles, by contrast, include roads, gas stations, and oil supply lines (use-infrastructures) as well as laws and conventions for driving (social institutions).

\subsection{Industrial Grounds and Conditions for Racial Hierarchy}

In theorizing race as an industrial technology, we advocate understanding racial classification and racial hierarchy as arising and persisting by virtue of grounds associated with industrial technologies, and as impacting members of various racial groups by virtue of conditions associated with those technologies. Consider, then, some of the industrial grounds for racial classification and racial hierarchy. The raw materials for racialized humans might include evolved dispositions for thinking about ethnies (Machery and Faucher). They almost certainly include human bodies. These bodies, as we theorize them, are not race-neutral: there is no race-free body anymore than there are lines without lengths or shapes without colors. We thereby follow Gill-Peterson in understanding human bodies as always and already racialized. We do not follow him, however, in taking this to erase boundaries between humans' bodies and their races, because we deny that necessary accompaniment requires blurring boundaries. We prefer, instead, to preserve conceptual distinctions-nominal though they might be-among human bodies and other grounds that sort those bodies into different racial groups.
Other grounds for racialized humans include race-producing and sustaining technicians, such as hate groups, politicians and media personalities who facilitate or fuel racial animosities, and various other agents of state power such as police officers. These technicians use an array of race-producing and sustaining techniques (Haney-Lopez). Fields and Fields characterize these techniques as racecraft, factors that "govern what goes with what and whom (sumptuary codes), how different people must deal with each other (rituals of deference and dominance), where human kinship begins and ends (blood), and how [humans] ... look at themselves and each other (the gaze)" (Fields and Fields 25, italics omitted). Race-technicians enact their race-crafting techniques through an array of race-producing and sustaining machinic institutions: laws, such as the 13th and 15th Amendments during Reconstruction (Fields 163); social policies, such as the racial profiling guidelines and practices of law enforcement agents as endorsed by Terry v. Ohio (1968) and various political parties (Fields 164); and segregated markets, such as race-specific medicine marketed to Latinx populations (Fields and Fields 49).

Consider, next, some of the industrial conditions for racial hierarchy and classification. Use-infrastructures include racial anxieties and fears, cultural knowledge of racial classification categories that elicits differential stereotyped responses to differently racialized humans. They also include continuing narratives of postracialism, which enable "civilized" racial oppression that is neither enshrined in law nor violent (Goldberg; Harvey). There are also social institutions with power to direct differential impacts toward various racialized groups. For example, there are public laws that encode differential privileges among racial group, as with Plessy v. Ferguson (1896). There are housing policies that enforce residential segregation by racial classification, stop and frisk policies that disproportionately target members of oppressed racial groups, and computergenerated metrics responsible for algorithmic racial discrimination (Benjamin, "Catching" 149-50). Further conditions include news and entertainment media, which publicize norms and expectations regarding differential privilege among racial groups through 
code words (Brooks and Hebert) or stereotypes and visuals (Mahtani); and "race corrections," whether by manufacturers with respect to worker compensation policies or by judges with respect to interpretations of law, whereby impacts of otherwise race-neutral social policies are "adjusted" in response to the racial classifications of the subjects of those policies (Benjamin, "Catching" 147-148).

\subsection{Empirical Fit}

We highlight only some of the grounds and conditions of racial hierarchy. Even these few factors, however, suffice to show that theorizing racial hierarchy as industrial technology accommodates the phenomena of racial passing and stationarity.

Our theoretical framework explains racial passing at the level of industrial conditions: one who passes has their race by virtue of membership in a particular group in a racial hierarchy, and yet experiences impacts associated with membership in a different group by virtue of being subject to conditions associated with that different group. For example, insofar as Coleman Silk (in Roth's novel The Human Stain) is a black man passing for white, he is black by virtue of race-producing and sustaining grounds making him so; but he receives the benefits of whiteness, and avoids the harms of blackness, by virtue of being subject to conditions associated with being Jewish. Such passing might involve, for instance, judges not "race correcting" legal penalties, or advertisers directing advertisement for "white people products" to his home address. It does not, however, involve changing his biology (as would be if he were theorized as a cyborg). The grounds that construct Silk as black remain the same, while the conditions that determine the impacts of his blackness change.

Our theoretical framework explains racial stationarity, by contrast, at the level of industrial grounds. The technicians, machinery, and machinic institutions that ground racial hierarchies are localized to specific times and geographical spaces. For example, the racial profiling guidelines and practices of law enforcement agents endorsed by Terry $v$. Ohio (1968) help to ground racial hierarchy in the United States but not in Brazil. So being black in New Orleans does not travel to being black in Brazil in part because the race-creating and sustaining laws that govern New Orleans do not travel to Brazil. And, more generally, race does not travel because many of its grounds do not travel. So, again, the New Orleanian's traveling does not involve changing his biology. The raw materials for constructing his race remain the same, while the grounds that determine which race is constructed from that material change.

Our explanations of racial passing and stationarity point toward a deep difference between racial passing and racial traveling: racial passing is possible because conditions for racial impact do not always track grounds for racial groupings, while racial travel is possible because grounds for racial grouping are spatially and temporally localized. Different grounds construct products with different capacities, and different conditions for the same product facilitate different impacts upon using the same capacities. For example, the grounds for automobiles include their component parts. Working parts impact capacities for functional vehicles; defective parts, for dysfunctional ones. The conditions for automobiles, by contrast, include roads and various driving regulations. Welldesigned conditions facilitate safe vehicular operations; ill-designed conditions, dangerous ones, even for vehicles that are functional. By analogy, the grounds for racial hierarchy sort individuals into different racial groupings, some more privileged and empowered than others. The conditions for racial hierarchy, by contrast, facilitate how those privileges and powers (or lack thereof) are experienced by individuals so sorted.

\section{Concluding Remarks}

Theorizing racial hierarchy as an industrial technology, and within a humanist framework, has several theoretical advantages to posthumanist cyborgand prosthetic-approaches to understanding race. First, it accommodates the phenomena of racial passing and stationarity. It does so in a way that is principled rather than ad hoc. It also does so in a way that preserves relevant conceptual differences between human 
bodies and their races. For example, our theoretical framework explains a deep difference between racial passing and racial traveling: racial passing is possible because conditions for racial impact do not always track grounds for racial groupings, while racial travel is possible because grounds for racial grouping are spatially and temporally localized. Neither the cyborg nor prosthetic posthumanist theorizations of race offer a similar explanation of such difference.

Second, theorizing racial hierarchy as an industrial technology provides a framework for organizing and integrating a wide array of research about race across a diverse range of disciplines. Our framework does this, in part, by virtue of distinguishing between grounds for racial hierarchies and conditions that facilitate the impacts of those hierarchies. It does so, as well, by virtue of identifying various distinct yet interrelated categories of ground and condition: technician, technique, raw material, and machinic institution in the case of grounds; use-infrastructure and social institution in the case of conditions.

Finally, theorizing racial hierarchy as an industrial technology preserves the benefits of posthuman approaches to racialized humans while avoiding their costs. For example, according to our approach, and in contrast to the cyborg approach, passing and traveling do not alter the biology of racialized persons. According to our approach, and in contrast to the prosthetic approach, racialized humans do not bear responsibility for their oppression; instead, that responsibility rests with the conditions that facilitate harmful and oppressive impacts-and with those who create or help to sustain those conditions. Again, according to our approach, but not according to the prosthetic approach, racialized humans cannot part from their racial grouping at will: they must travel to a time or place with different grounds for racial hierarchy, thereby changing their race; or they must be fortunate enough to pass, benefiting from the indeterministic fit between racial grouping and conditions that facilitate impacts thereof. Finally, our approach, unlike other posthuman approaches, draws attention to impersonal machinic and social institutions responsible for creating, sustaining, and shaping the impacts of racial hierarchy.
For these reasons-of empirical fit, crossdisciplinary organization, and theoretical virtue-we recommend understanding racial hierarchy within a humanistic framework and as an industrial technology. Doing so provides a powerful, and largely unexplored, critical scheme for scrutinizing the present and imagining better futures. It guides us, for example, to focus on grounds if we desire to understand better where race comes from, but to focus instead on conditions if we desire to combat harmful impacts of racial hierarchy.

\section{Acknowledgements}

We thank our anonymous reviewers for helpful and constructive comments.

\section{References}

Alfaro, Arantxa, Ángela Bernabeu, Carlos Agulló, Jaime Parra, and Eduardo Fernándo. "Hearing Colors: An Example of Brain Plasticity." Frontiers in Systems Neuroscience 9, article 56, 2015.

Bashi, Vilna. "Racial Categories Matter Because Racial Hierarchies Matter: A Commentary." Ethnic and Racial Studies 21, 5 (1998): 959-968.

Bashi, Vilna and Antonio McDaniel. "A Theory of Immigration and Racial Stratification." Journal of Black Studies 27, 5 (1997): 668-682.

Benjamin, Ruha. "Catching Our Breath: Critical Race STS and the Carceral Imagination." Engaging Science, Technology, and Society 2 (2016): 145-156.

"Innovating Inequality: If Race is a Technology, Postracialism is the Genius Bar." Ethnic and Racial Studies 39, 13 (2016): 2227-2234.

Braidotti, Rosi. The Posthuman. Malden, MA: Polity Press, 2013.

"Posthuman, All Too Human: Towards a New Process Ontology." Theory, Culture \& Society 23, 7-8 (2006): 197-208.

Brooks, Dwight E. and Lisa P. Hebert. "Gender, Race, and Media Representation. The SAGE Handbook of Gender and Communication, ed. B.J. Dow and J.T. Wood. Sage, 2006. 297-317.

Césaire, Aimé. Discourse on Colonialism. Translated by Joan Pinkham. New York: Monthly Review Press, 2000.

Chun, Wendy Hui Kyong. "Introduction: Race and/as technology; or, How to Do Things with Race." Camera Obscura 24, 1 (2009): 7-35. 
Coleman, Beth. "Race as Technology." Camera Obscura 24, 1 (2009): 176-207.

Conley, Dalton. Being Black, Living in the Red: Race, Wealth, and Social Policy in America. Berkeley: University of California Press, 2010.

De Lauretis, Teresa. Technologies of Gender: Essays on Theory, Film, and Fiction. Bloomington: Indiana University Press, 1987.

Downey, Gary Lee, Joseph Dumit, and Sarah Williams. "Cyborg Anthropology." Cultural Anthropology 10, 2 (1995): 264-269.

Edwards, Sue Bradford and Duchess Harris. Black Lives Matter. Minneapolis: Abdo Publishing, 2016.

Ellul, Jacques. The Technological Society. New York: Vintage Books, 1964.

Ferrando, Francesca. "Posthumanism, Transhumanism, Antihumanism, Metahumanism, and New Materialisms: Differences and Relations." Existenz 28, 2 (2013): 26-32.

Fields, Barbara J. "Ideology and Race in American History." J. Morgan Kousser and James M. McPherson, eds. Region, Race, and Reconstruction: Essays in Honor of C. Vann Woodward. New York: Oxford University Press, 1982. 143-177.

Fields, Karen E. and Barbara J. Fields. Racecraft: The Soul of Inequality in American Life. New York: Verso, 2010.

Foucault, Michel. "Technologies of the Self." Ethics: Subjectivity and Truth. Paul Rabinow, ed. New York: The New Press, 1997. 223-228.

Gill-Peterson, Julian. "The Technical Capacities of the Body: Assembling Race, Technology, and Transgender." TSQ: Transgender Studies Quarterly 1, 3 (2014): 402418.

Ginsberg, Elaine, ed. Passing and the Fictions of Identity. Durham: Duke University Press, 1996.

Goldberg, David Theo. Are We All Postracial Yet? Malden, MA: Polity Press, 2015.

Gordon, Lewis. "African-American Philosophy: Theory, Politics, and Pedagogy." Philosophy of Education 1998, 1998, pp. 39-46. http://ojs.ed.uiuc.edu/index.php/pes/ article/view/2082/777 (accessed 2 May 2017).

Griffith, Aaron M. "Social Construction and Grounding." Philosophy and Phenomenological Research, forthcoming.

Haney-Lopez, Ian F. “The Social Construction of Race: Some Observations on Illusion, Fabrication, and Choice." Harvard Civil Rights-Civil Liberties Law Review 29 (1994): 1-62.
Haraway, Donna J. Simians, Cyborgs, and Women: The Reinvention of Nature. New York: Routledge, 1991.

Harvey, Jean. Civilized Oppression. Lanham, MD: Rowman and Littlefield Publishers, 1999.

Hayles, N. Katherine. How We Became Posthuman: Virtual Bodies in Cybernetics, Literature, and Informatics. Chicago: University of Chicago Press, 1999.

Jackson, Zakiyyah Iman. "Animal: New Directions in the Theorization of Race and Posthumanism." Feminist Studies 39, 3 (2013): 669-685.

"Outer Worlds: The Persistence of Race in Movement 'Beyond the Human," GLQ: A Journal of Lesbian and Gay Studies 21, 2-3 (2015): 215-218.

Kennedy, Randall. "Racial Passing." Ohio State Law Journal 62 (2001): 1145-1173.

Kroeger, Brooke. Passing: When People Can't Be Who They Are. New York: Public Affairs, 2004.

Kull, Anne. "The Cyborg as an Interpretation of CultureNature." Zygon 36,1 (2001): 49-56.

Machery, Edouard and Luc Faucher. "Social Construction and the Concept of Race." Philosophy of Science72, 5 (2005): 1208-1219.

Magee, Joe C. and Adam D. Galinsky. "Social Hierarchy: The Self-Reinforcing Nature of Power and Status." The Academy of Management Annals 2, 1 (2008): 351-398.

Mahtani, Minelle. "Representing Minorities: Canadian Media and Minority Identities." Canadian Ethnic Studies 33, 3 (2001): 99-133.

Mallon, Ron. "Passing, Traveling, and Reality: Social Constructionism and the Metaphysics of Race." Nous 38, 4 (2004): 644-673.

Mills, Charles W. Blackness Visible: Essays on Philosophy and Race. Ithaca: Cornell University Press, 1998.

Neville, Helen A., Miguel E. Gallardo, and Derald Wing Sue (eds.). The Myth of Racial Color Blindness: Manifestations, Dynamics, and Impact. Washington, D.C.: APA Press, 2016.

Pearlman, Ellen. "I, Cyborg." PAJ: A Journal of Performance and Art 37, 2 (2015): 84-90.

Pearson, Greg and A. Thomas Young, eds. Technically Speaking: Why All Americans Need to Know More about Technology. Washington, D.C.: National Academy Press, 2002.

Puar, Jasbir K. "'I would rather be a cyborg than a goddess:" Becoming-Intersectional in Assemblage Theory." philoSOPHIA 2, 1 (2012): 49-66.

Reardon, Jenny. Race to the Finish: Identity and Governance in the Age of Genomics. Princeton: Princeton University Press, 2005. 
Rhee, Margaret. "In Search of My Robot: Race, Technology, and the Asian American Body." Scholar \& Feminist Online 13, 3 (2016). http://sfonline.barnard.edu/ traversing-technologies/margaret-rhee-in-search-ofmy-robot-race-technology-and-the-asian-americanbody/0/ (accessed 2 May 2017).

Root, Michael. "How We Divide the World." Philosophy of Social Science 67 (2000): 628-639.

Roth, Philip. The Human Stain. New York: Vintage Books, 2000.

Sandoval, Chela. "New Sciences: Cyborg Feminism and the Methodology of the Oppressed." The Cyborg Handbook. Chris H. Gray, Heidi J. Figueroa-Sarriera, and Steven Mentor, eds. New York: Routledge, (1995): 407-422.

Santos, Ricardo Ventura, Peter H. Fry, Simone Montiero, Marcos Chor Maio, José Carlos Rodrigues, Luciana Bastos-Rodrigues, and Sérgio D.J. Pena. "Color, Race, and Genomic Ancestry in Brazil: Dialogues between Anthropology and Genetics." Current Anthropology 50, 6 (2009): 787-819.

Schueller, Malini Johar. "Analogy and (White) Feminist Theory: Thinking Race and the Color of the Cyborg Body." Signs 31, 1 (2005): 63-92.

Sheth, Falguni. "The Technology of Race." Radical Philosophy Review, vol. 7, no. 1, 2004, pp.77-98.

Sheth, Falguni A. Toward a Political Philosophy of Race. Albany: SUNY Press, 2009.

Sinclair, Bruce, ed. Technology and the African-American Experience: Needs and Opportunities for Study. Cambridge, MA: MIT Press, 2004.

Song, Miri. "Racial Hierarchies in the USA and Britain: Investigating a Politically Sensitive Issue." Researching Race and Racism. ." Martin Bulmer and John Solomos, eds. New York: Routledge, (2004): 172-186.

Thweatt-Bates, Jeanine. Cyborg Selves: A Theological Anthropology of the Posthuman. Burlington, VT: Ashgate, 2012.

Vogel, Todd. Rewriting White: Race, Class, and Cultural Capital in Nineteenth-Century America. Piscataway, NJ: Rutgers University Press, 2004.

Wilkerson, Abby. "Ending at the Skin: Sexuality and Race in Feminist Theorizing." Hypatia 12, 3 (1997): 164-173. 